\title{
Problems and Countermeasures of Northeast University in Serving the Revitalization of Northeast Old Industrial Bases
}

\author{
Chunqiu Xu \\ 1699 Donghua Street, Shuangyang District, Changchun City, Jilin Province, China \\ xcq_2006@163.com
}

\begin{abstract}
Keywords: Northeast University; Social Service Function; Northeast Old Industrial Base Revitalization; Production and Research Combined
\end{abstract}

\begin{abstract}
This paper studies the problems and countermeasures in the revitalization of the Northeast Old Industrial Base of China. On the basis of premise of the role of the Northeast University in the revitalization of the Northeast Old Industrial Base, the purpose of the study is to analyze problems of Northeast University Serving in the Revitalization of the Northeast Old Industrial Base, On the basis of this, put forward the countermeasures to enhance the Northeast University to serve in the revitalization of the Northeast Old Industrial Base, with a view to speed up the revitalization of the Northeast Old Industrial Base. The main research methods adopted in this paper include literature research method, investigation method, comparative analysis method and experience summary method. The conclusion of this paper is that the education of northeast colleges and universities should convey the "suitable" talents for the local economic construction according to the needs of the revitalization of the Northeast Old Industrial Base of China. Scientific research work should provide intellectual support for local economic construction, strengthen the combination of production, teaching and research, improve the ability of colleges and universities to serve the revitalization of the Northeast Old Industrial Base.
\end{abstract}

\section{Introduction}

The Northeast Old Industrial Base of China was the cradle of new Chinese industry. It has made a historic and important contribution to the establishment of an independent and complete industrial system and a national economic system and for Reform and Opening and modernization .However, with the deepening of the development of market economy, the contradictions of institutional and structural of the Northeast Old Industrial Base is becoming more and more serious, the technological innovation capability of enterprises is seriously insufficient, the resource-dependent industry is declining and the market competitiveness is low. These problems seriously restrict the pace of economic development, Northeast Old Industrial Base transformation is imperative. The revitalization of the old industrial base, an important condition is the support of talent and technology, and higher education has always been the cradle of talent and technology, especially with the rise of the knowledge economy and the improvement of social information, economic and social development more and more relying on the cultivation of talents in colleges and universities and the development of scientific and technological work.

\section{Role of Northeast University in the Revitalization of the Northeast Old Industrial Base}

Northeast University Provide the Correct Ideas and Theories for the Revitalization of the Northeast Old Industrial Base. Revitalize the northeast old industrial base, it has to adapt to the requirements of the establishment of a socialist market economic system, to adapt to changes in economic growth requirements, to use new ideas, explore new ways ,establish a new mechanism. Northeast University has a unique human and intellectual resources, should be based on the northeast of the geographical position, business status and resources, with the local government departments to form a joint policy research team, Vigorously carry out research on countermeasures, especially on the following aspects of research : The elimination of institutional barriers to meet the requirements of the development of market economy; adjust the ownership structure and industrial 
structure, to resolve structural contradictions; formulate industrial policy, the introduction of strategic investors; promote entrepreneurship and promote rapid economic development[1].

Northeast University Provide Much-Needed Talent for the Revitalization of the Northeast Old Industrial Base. Talent is an important guarantee for the revitalization of the Northeast Old Industrial Base. Colleges and universities as the carrier of all kinds of talent, shouldering the task of providing talent for the old industrial base. According to the actual situation of the Northeast Old Industrial Base, colleges and universities should focus on cultivating the following talents: cultivating high-level international management personnel with innovative thinking, leading talents of science and technology and talents of scientific and technological innovation; cultivating talents that are good at using hi-tech knowledge to solve practical problems ; cultivating talents that understand technology, will operate the skills in the production line; cultivating all kinds of talent shortage for transformation of the northeast old industrial base[2].

Northeast University Provide Scientific and Technological Support for the Revitalization of the Northeast Old Industrial Base. Most of the large and medium-sized enterprises in the Northeast Old Industrial Base have no serious ability to innovate, and some large and medium-sized enterprises have not established a strong technical center. The technology research and development funds of the enterprises are low and the technologies of independent intellectual property rights are rarely formed. The enterprises themselves can not become technological innovation subject. Colleges and universities as a knowledge innovation, knowledge production, knowledge dissemination and knowledge application base, with scientific and technological innovation talent, base, environment and other advantages, should be the transformation of the Northeast Old Industrial Base to provide scientific and technological support. The use of a large number of scientific and technological achievements have been made to technology services to achieve the transfer to the enterprise to promote the transformation of scientific and technological achievements. Through various forms of university and enterprise joint and production and research cooperation, from the enterprises need to select the subject, for enterprises to solve problems, promote scientific research and industrialization. Play the role of science and technology of the University, founder or joint technology enterprises, direct service to the local economy. The use of university science and technology park of scientific and technological achievements into the realization of the carrier and the role of industrialization, to achieve the interactive development of colleges and universities[3].

\section{Problems of the Northeast Colleges and Universities Serve in the Revitalization of the Northeast Old Industrial Base}

Talent Supply of Colleges and Universities Do Not Match the Market Demand. Talent structure is unreasonable, this is an important reason that the industrialization level is not high of the northeast. Personnel training, the professional training of institutions of higher learning should not only meet the academic requirements, but also to meet the needs of the community for the relevant personnel. However, the current training objectives of colleges and universities in colleges and universities are not matched with the market demand in the northeast universities. The main reason is that the subject and professional structure of colleges and universities in northeast of China are not compatible with the actual requirements of revitalizing the old industrial bases in Northeast of China. The existing personnel training structure and economic construction needs do not match, the number of new disciplines and varieties of slow growth and other issues[4].

The Scientific Research Results of University Teachers are Strong in Theory and Poor in Applicability. Especially in the study of humanities and social sciences, people's research is mostly from theory to theory, confined to purely academic field, some theories are too idealistic, or even simply fantasy. The proposed policy recommendations are poorly targeted and operational. The development of contemporary high-tech, on the one hand to break the strict boundaries between science and technology, the emergence of a number of highly knowledge-intensive, highly disciplined, scientific and technological integration of high-tech fields, such as information science and technology, life science and technology, New materials science and technology. Science, technology, economic development characteristics and internal relations, requires the university's 
scientific research across the boundaries between disciplines, across the boundaries between science and technology, and even across the boundaries between universities and enterprises.

The Degree of Integration Between Universities and Industry is Poor. The combination of universities and industries is a process of intellectual materialization and intellectual capitalization. Intellectual capital in the national economy and social life play a role in the most direct and fundamental way is the materialization of knowledge. It requires strengthening the university foreign cooperation and exchange mechanism. In the process of going to entrepreneurial universities, many of the corresponding universities and industry mixed institutions were generated. In order to strengthen the relationship between universities and industry, they created organizational guarantee for the formation of entrepreneurial universities. In the era of knowledge economy, more and more universities have entered the market through the transfer of scientific and technological achievements, engaged in scientific and technological development and science and technology services, or through the establishment of school-run enterprises, production of products to enter the market. The university has long been a closed self-sufficient system, its participation in the economic operation of the way more and more broad. Therefore, the University should strengthen the research strength at the same time, strengthen the government fund projects and industry cooperation under the awareness of regional economic and social development services, see Figure $1[5]$.

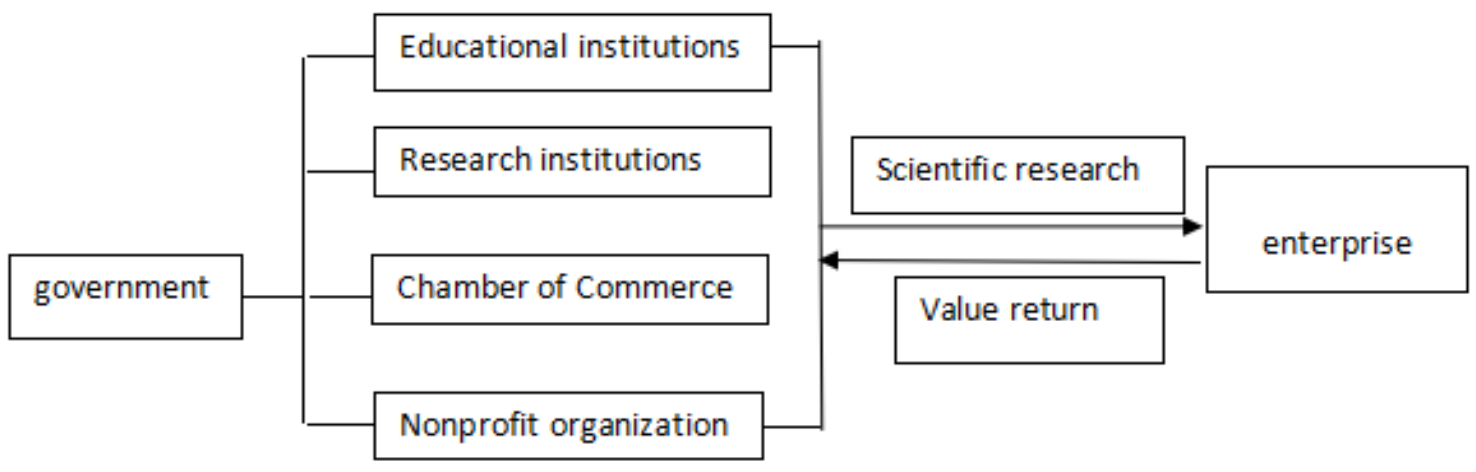

Figure 1. Intellectual capital promotes the development of enterprises and regions

\section{Countermeasures to Enhance the Northeast Local Colleges and Universities to Serve the Northeast Old Industrial Base in the Revitalization}

The Education of Northeast Colleges and Universities should Transport "Suitable" Talents for Local Economic Construction. Combined with reality, clear "application-oriented" personnel training objective. The cultivation of talents in northeast colleges and universities is both applicable and research. Research, that is, academic, to cultivate teaching and research talent as the goal; application type, that is, to cultivate practical talents as the goal. Colleges and universities should aim at the actual needs, clear personnel training objectives, undergraduate, specialist education should be training application talents as a school orientation and training objectives, see Table 1[6].

According to the needs of society, rational design courses. Curriculum design relations students access to knowledge of the way, curriculum should be reasonable and effective. Course settings to fully consider the real needs, constantly updated, in order to teach students the most practical and most innovative knowledge. Which should include a large number of practical courses, to develop students' practical ability. In addition the number of courses should not only allow students to have a certain discretionary time, letting them have the pressure to learn to give students self-learning space to exercise students' ability to innovate independently[7].

Paying Attention to Social Practice and Improving Students' Professional Ability. College disciplines should pay attention to social practice, by letting students out of the campus, to the community to exercise, to develop students basic quality and professional skills. And should pay attention to the effectiveness of internships, that is, after the end of social practice, students should be unified test results, you can consider the use of a unified examination in the form of students 
according to their own practice areas to choose to answer.

Table 1 Effective Measures for College Graduates to Promote Employment

\begin{tabular}{|c|c|c|}
\hline & $\begin{array}{c}\text { Number of } \\
\text { samples }\end{array}$ & percentage \\
\hline $\begin{array}{c}\text { Strengthen support and guidance, broaden employment } \\
\text { channels, improve employment needs }\end{array}$ & 3548 & $31.4 \%$ \\
\hline Reform higher education and improve employ ability & 2152 & $19.0 \%$ \\
\hline Change the concept of employment & 1145 & $10.1 \%$ \\
\hline Encourage independent entrepreneurship & 1082 & $9.6 \%$ \\
\hline Improve the allocation of human resources market capacity & 881 & $7.8 \%$ \\
\hline Strengthen employment coordination management & 680 & $6.0 \%$ \\
\hline Strengthen supervision and maintain employment fairness & 610 & $6.0 \%$ \\
\hline Strengthening the Employment Service for College Graduates & 587 & $5.2 \%$ \\
\hline Strengthen employment assistance and employment assistance & 450 & $4.0 \%$ \\
\hline others & 162 & $1.5 \%$ \\
\hline
\end{tabular}

Scientific Research of the Colleges and Universities Work Provide Intellectual Support for the Local Economic Construction. Establish the concept of services local economic and social development. Scientific research in colleges and universities should adhere to the concept of "based on local and service places", and effectively change the concept of sticking to the campus, strengthen the function of serving the local society, persist in practicality and application, and firmly establish the service of local economic construction and social development thought of. This is conducive to local economic construction, promote local development; the other hand, the university itself can also get the attention and support of local governments, improve the external environment and school conditions, accelerate the development of the school[8].

Guide the content of scientific research tilt to the economic construction. University scientific research institutions should be guided in the policy to guide teachers to local economic construction and social development services as their focus and foothold. To guide teachers and other scientific research personnel in close connection with the actual needs of local economic and social development, the local economic and social development of outstanding problems, hot issues as the focus of research topics and the main direction, especially focusing on applied research and countermeasures research, focus on solving practical problems, The university scientific research into the local economic construction of the "think tank"[9].

Strengthen links between scientific research and local real. Colleges and universities should guide teachers out of the school, strengthen the theoretical departments and the substantive departments of the exchange and link to promote the transformation of the results of the project. At the same time smooth the school and the local state organs, enterprises and institutions, social organizations, contact channels, through various forms to promote research results, to play a practical role.

Strengthen the Combination of Production and Research, Improve the Ability of Colleges and Universities to Serve the Revitalization of the Northeast Old Industrial Base. Colleges and universities themselves: enhance awareness, optimize the training model, improve scientific research conversion rate. Colleges need to improve the conversion rate of scientific research, service enterprises and local economic development. To encourage researchers to "go out", close with the business and social contact, in-depth understanding of the real needs, from the better to promote scientific research results.

Enterprises and other institutions: close contact with universities, strengthen cooperation between the two sides. For the enterprise, they need close ties with universities, strengthen 
cooperation between the two sides to achieve mutual complementarity. First of all, enterprises should establish a long-term communication mechanism with colleges and universities through this mechanism to reflect the relevant scientific research problems, talent needs, etc., so that colleges and universities to arrange related research and teaching matters; Second, enterprises in scientific research, but also Do the role of "investors". At present, university research funding mainly comes from government investment. If the research funds come from the enterprise, as an "investor" of the enterprise, it is clear that the practical value of scientific research results can be better to promote the combination of production and research; Third, enterprises can also provide the necessary internship positions for college students Improve their quality and practical ability to promote the "production" and "learning" combination [10].

\section{References}

[1] Liu Jixiang, The Role and Influence of Local Colleges and Universities in the Process of Regional Economic Integration, Journal of Tangshan Normal University, (2016) No. 5.

[2] Qiu Lei, The Role of Higher Vocational Education in Urban Transformation and Local Economic Development, Industrial Technology and Vocational Education, (2015) No. 1.

[3] Yang Chunlin, Analysis of the Role of Local Colleges and Universities in the Development of Local Economy, Youth and society, (2014 )p.152.

[4] Shen Yafeng, Research on the Interactive Development of Local Colleges and Regional Economy, Journal of Xinxiang University, (2016) No. 7.

[5] Li Shulin, Research on the Countermeasures of Colleges and Universities Serving Local Economic and Social Development, Discussion and Practice of Educational Teaching Method, (2014) No. 8.

[6] Liu Jianghong, The Countermeasures and Practice of Colleges and Universities in Serving Local Economy, Research on Management Strategy, (2013) p.9-10.

[7] Li Xiuyun, Reflections on Local Colleges and Universities in China serving the Regional Economic Development, Theoretica observation, (2015) No.9.

[8] Bao Yanyu, Research on the Cultivation of Applied Talents in Local Colleges and Universities Based on Regional Economic Development, (2015) p.218-219.

[9] Yang Yang, Research on the Problems and Countermeasures of Colleges and Universities service in Local Economic Development, Management Writing, (2012) No. 28.

[10]Ma Ding, Problems and Suggestions on Current Service of Colleges and Universities in Local Economic Construction, Economic Research Guild, (2012) No. 17. 